\title{
DEMOGRAFIA DEL CENSO \\ DE FLORIDABLANCA. \\ UNA APROXIMACION
}

\author{
FAUSTO DOPICO \\ Universidad de Santiago \\ ROBERT ROWLAND \\ Instituto Universitario Europeo \\ (Florencia)
}

\section{Introducción}

Es todavía mucho lo que ignoramos acerca de la demografía española en el siglo xviII, pese a contar con una serie de trabajos de gran interés, y distinta significación, como los de M. Livi Bacci (1968), F. Bustelo (1972 a y b), V. Pérez Moreda (1980) y J. Nadal (1984). No se trata sólo de que persistan numerosos interrogantes sobre los niveles de fecundidad y mortalidad, sino que ni siquiera hay acuerdo entre los investigadores sobre el grado de ocultación de los distintos censos y vecindarios, y por lo tanto son todavía objeto de discusión aspectos tan fundamentales como el volumen mismo de la población y su tasa de crecimiento.

El cálculo de una serie de estimadores demográficos suficientemente fiables parece necesario para situar la sociedad española en el contexto europeo y comprender mejor los avatares de su posterior proceso de modernización económica y social. Además, los estudios sobre los comportamientos demográficos en la Península Ibérica se están revelando como especialmente importantes para entender las semejanzas y las disparidades de los regímenes demográficos y los sistemas domésticos de la Europa occidental y la Europa mediterránea '.

Existe un número bastante elevado de monografías locales, la mayoría basadas en el análisis no nominativo de los registros parroquiales, que nos ofrecen datos sobre la evolución de la población o sobre las crisis demográficas, pero, por sí mismas, no posibilitan ir muy lejos en el análisis de las variables vitales. Los estudios basados en las técnicas de reconstrucción de familias son mucho más escasos, y no siempre convincentes. En espera de una gran encuesta planificada, como la del INED en Francia o la de Wrigley y Schofield en Inglaterra, cualquier análisis significativo a nivel español o regional ha de basarse fundamentalmente en la información censal disponible.

\footnotetext{
' R. Rowland (1984 y s. f.).
} 
La España de la segunda mitad del siglo xviII es bastante afortunada en este sentido. Disponemos de tres censos generales - Aranda (1768), Floridablanca (1787) y Godoy (1797) - que no sólo nos ofrecen los efectivos totales, sino también los grandes rasgos de su distribución por edades.

De los tres censos citados, el de Floridablanca ha tenido una buena aceptación entre los investigadores. En 1965, P. Vilar lo calificaba de «admirable» para su época, y poco después M. Livi Bacci (1968) lo utilizaba ampliamente en su estudio para el proyecto de Princeton. Más tarde, F. Bustelo (1972 b), V. Pérez Moreda (1986) y R. Rowland (1988), han extraído de él diversos resultados de carácter global, y ha sido utilizado asimismo como fuente básica en numerosos estudios regionales y comarcales ${ }^{2}$. La mayoría de los investigadores coinciden en que sus cifras ofrecen una mayor fiabilidad, aunque en algunas áreas ésta parece similar a la de Godoy ${ }^{3}, y$, en ciertos aspectos, como en su clasificación de la población activa, es superado por este último.

José Moñino, Conde de Floridablanca, conocía bien el temor de los súbditos del Reino a ser empadronados, por lo que cuando, en el verano de 1786, ordenó la elaboración del censo, advirtió que los agentes debían visitar cada pueblo «calle ita», es decir, calle por calle y casa por casa, anotando el número de individuos, su edad, estado civil y oficio, «sin tomar por ello sus nombres» (Real Orden de 25 de julio de 1786); indicación esta última que no siempre fue cumplida. La información requerida fue recogida, bajo la responsabilidad de las autoridades locales y con la ayuda de los párrocos, en los meses finales de $1786 \mathrm{y}$, en algunos casos, a comienzos de 1787.

Hay bastantes indicios, como ya hemos apuntado, de que el Censo de Floridablanca es excelente para su época, y recientemente $M$. Livi Bacci (1987) ha vuelto a insistir en el carácter pionero de su concepción y su realización. Naturalmente, se trata de un censo destinado a conocer los efectivos de la población, que la sensibilidad populacionista del despotismo ilustrado español identificaba a la «fuerza interior del estado», según refleja la misma orden de Floridablanca. Por consiguiente, y pese a que se ha insistido en la «modernidad» del censo, no fue realizado por un organismo estadístico especializado, ni se adapta a los cánones que un demógrafo desearía.

A pesar de su carácter protoestadístico, el censo de Floridablanca puede constituir un instrumento precioso para el conocimiento de la población española en el siglo xviır. Disponer de la estructura de edades de una po-

2 S. Llobet (1947); P. Vilar (1964-68); J. Iglesies (1969-70); E. Fernández de Pinedo (1974); F. Bustelo (1974, 1975 y 1978); J. E. Castelló (1978); F. Jiménez de Gregorio (1980); A. García-Sanz Marcotegui (1985); E. Lluch (1981); G. Pérez Sarrión (1984); A. Moreno Almarcegui, J. Soler Serratosa y F. Fuentes Robles (1984).

${ }^{3}$ E. Fernández de Pinedo (1974). 
blación, aunque se trate de una agrupación no estándar y algo imprecisa, abre grandes posibilidades al análisis demográfico. Desde que Lotka publicó sus trabajos sobre la teoría de las asociaciones en las poblaciones humanas, sabemos que la composición por edades es un vestigio de la historia demográfica de las generaciones presentes, y que ese vestigio puede adquirir un valioso significado cuando conocemos algún parámetro demográfico adicional.

El objetivo de este estudio, como su mismo título indica, es efectuar una aproximación al conocimiento de la demografía española del siglo xvirI mediante la aplicación a los datos del Censo de Floridablanca de técnicas de análisis basadas en las características conocidas de las poblaciones estables. El ejercicio presupone la coherencia interna de los datos, y los resultados alcanzados se refieren a la representación que el mencionado censo nos ofrece de la población de la época. Los ofrecemos sin otras pretensiones que el de haber intentado extraer, de la información alli contenida, una serie de indicadores demográficos de ámbito regional. Investigaciones futuras a nivel local y regional permitirán una evaluación más segura de nuestras estimaciones, confrontándolas con la información contenida en otras fuentes.

\section{La metodología de las poblaciones estables y la estimación de los niveles de mortalidad}

La primera dificultad para la evaluación de los datos reside en el registro de la edad. Esta se recoge "poco más o menos», como advierte la misma edición del censo; y, además, la agrupación de edades resulta ambigua. El censo clasifica los habitantes por su edad hasta los siete años, de 7 a 16 , de 16 a 25 , de 25 a 40 , de 40 a 50 y de 50 arriba, con lo que los extremos de los intervalos resultan imprecisos, y así lo eran probablemente para los agentes que registraron los datos. Ya que las mediciones del nivel de mortalidad son bastante sensibles respecto a este problema, hemos realizado los cálculos correspondientes para las dos interpretaciones posibles (es decir, 0-6, $7-15,16-24,25-39,40-49$ y 50 y más, por una parte; y 0-7, 8-16, 17-25, $26-40,41-50$ y 51 y más, por la otra), presentando finalmente la media aritmética de ambas. Este modo de proceder, junto con la misma composición de los primeros grupos de edades, ayuda asimismo a minimizar los tan frecuentes errores de redondeo. En lo que se refiere a los indicadores de fecundidad, las variaciones en los resultados son muy pequeñas de una a otra agrupación, una vez fijado el nivel de mortalidad, por lo que hemos tomado la primera de las citadas anteriormente, que viene a ser la utilizada habitualmente para los censos de la segunda mitad del siglo xvirl desde el trabajo de J. Ruiz Almansa (1947). 
Un segundo problema se centra en la contabilización de la llamada «población institucional», o población que vivía en comunidades. En la orden anteriormente citada se disponía su inclusión en la enumeración general de edades, pero los recopiladores del censo consideraron, sin embargo, que no se hallaba contabilizada y la sumaron al número de individuos procedentes de la clasificación por edades. Los estudios locales y regionales muestran que en algunas zonas sí se halla incluida, al menos parcialmente ${ }^{4}$, y en otras no ${ }^{5}$. Esta cuestión es, sin duda, relevante para aspectos tales como el cálculo de la tasa de crecimiento, de la estimación de la mortalidad adulta a partir de censos sucesivos o la evaluación de las tasas de migración. Tiene, por el contrario, una importancia secundaria cuando analizamos la estructura de edades. Entre la población que vive en hospicios, hospitales y otras comunidades hay adultos y niños en una proporción que posiblemente no altera mucho la distribución por edades. Existe, sin embargo, un sector constituido por los religiosos profesos que debe ser considerado como formado por adultos. En los cálculos sucesivos, se ha seguido el criterio de añadir el 75 por 100 de la población institucional, repartiendo los religiosos profesos de forma proporcional entre los grupos de edades adultas y los restantes entre todos los grupos. En cualquier caso, el error que se puede cometer de esta forma altera muy poco la composición por edades final, especialmente en el sexo femenino, donde el número de religiosas no alcanza el 0,5 por 100 .

El pionero estudio de M. Livi Bacci (1968) sobre el descenso de la fecundidad en España basa una buena parte de sus resultados y conclusiones en la aplicación al Censo de Floridablanca de la teoría de las poblaciones estables. Esta teoría estaba entonces en pleno apogeo entre los estudiosos de la población de los países con deficientes estadísticas demográficas. Desarrollos posteriores, en parte sugeridos por la propia teoría, y la posibilidad de realizar encuestas o de perfeccionar los cuestionarios de los censos, han llevado a la aparición de métodos alternativos. En los estudios históricos, la metodología desarrollada en torno a la teoría de las poblaciones estables conserva una gran potencialidad para ofrecernos aproximaciones de los parámetros demográficos, o para contrastar las estimaciones obtenidas por otras vías.

Una noción teórica de gran utilidad es la de población casi malthusiana o parcialmente estable. Se trata de las poblaciones con distribuciones por edad invariables en el tiempo. La condición es más débil que la exigida por el cóncepto de población estable (que debe poseer leyes de mortalidad y fecundidad constantes). Las poblaciones parcialmente estables gozan de la propiedad de que en cada momento guardan las mismas relaciones entre la

4 E. Fernández de Pinedo (1974); G. Pérez Sarrión (1984); A. García-Sanz Marcotegui (1985).

${ }^{3}$ A. García Sanz (1974); J. E. Castelló (1978). 
fecundidad, la mortalidad y la distribución por edad que la población estable correspondiente. Por lo tanto, en aquellos fenómenos en que intervienen estos factores, este tipo de poblaciones poseen las propiedades de las poblaciones estables ${ }^{\circ}$.

Una población real puede ser considerada una población parcialmente estable cuando ha sufrido escasas variaciones en su fecundidad y no ha estado afectada por una mortalidad diferencial de crisis que haya trastocado la composición por edades. Estas condiciones pueden encontrarse no sólo en algunos países subdesarrollados actuales, sino también en poblaciones correspondientes al antiguo régimen demográfico.

Ya M. Livi Bacci (1968) y F. Bustelo (1972 b) observaron que la distribución por edades de los censos de Aranda, Floridablanca y Godoy era aproximadamente estable, y el empleo de índices de similitud asi lo pueden confirmar. La definición de población parcialmente estable requiere, además, la no existencia de migración; aun cuando es posible la generalización y adaptación de parte de los resultados de la teoría de las poblaciones estables a sociedades con movimientos migratorios ${ }^{7}$. En la España de la segunda mitad del siglo xviII, éstos alcanzaron magnitudes significativas, sobre todo a nivel interregional, afectando de manera diversificada a los distintos colectivos. El hecho de que la migración era fundamentalmente masculina nos ayuda a superar esta dificultad, permitiendo la obtención de buenas aproximaciones de los parámetros estimados, mediante la utilización exclusiva, a estos efectos, de la población femenina.

Un aspecto primordial en la metodología que estamos utilizando es la determinación de la tasa de crecimiento de la población. Livi Bacci seleccionó la tasa de 0,43, que es la que se deduce de los censos de Aranda y Godoy. Esta tasa ha sido frecuentemente admitida con posterioridad, pese a que nunca ha podido establecerse fehacientemente que los dos censos, elaborados por distintas autoridades y bajo diferentes criterios, tengan la misma subestimación relativa.

El método a seguir por nuestra parte consistirá en realizar una estimación máxima y otra mínima, y calcular la media de los resultados obtenidos. Una tasa de crecimiento mínima puede ser la deducida al comparar los efectivos de la población de la corona de Castilla según el Censo de Ensenada, realizado a mediados de siglo, y el de Floridablanca; lo que nos da una tasa de crecimiento acumulativa anual del 0,29 por $100^{8}$. Hay dos tipos de motivos para creer que la población española creció a un ritmo mayor;

Naciones Unidas (1970).

N. Keyfitz (1977); M. Sivamurthy (1982).

- Grupo 75 (1977). 
por una parte, el Censo y el Catastro de Ensenada fueron realizados con una gran meticulosidad, y posiblemente aquél posee una cobertura mayor que el de 1787. Por otra parte, la población de la corona de Aragón parece haber crecido más en estos años que la castellana. Por otra parte, tomaremos como tasa máxima de crecimiento la derivada de comparar los censos de Aranda y Floridablanca, pues hay un consenso general acerca de la menor cobertura del primero. Esta última tasa se sitúa en el 0,59 por 100 .

Dada una tabla de mortalidad y una tasa de crecimiento, existe una, y sólo una, población estable cuya tasa de crecimiento intrínseca coincide con la tasa seleccionada. Nuestra forma de proceder, en este caso, será la inversa. Conocida la composición por edades de la población real y la tasa de crecimiento, trataremos de hallar la población estable que mejor aproxima aquélla, y, por consiguiente, la tabla de mortalidad que la origina. Necesitamos, para ello, poseer un conjunto de tablas tipo. Sabemos que la mortalidad de la población española y la de todas las regiones históricas en la década de 1860 sigue el modelo Sur de las tablas de Coale y Demeny. Como en los cien años anteriores a esta fecha no parece que se hayan producido cambios radicales en la estructura de la mortalidad, resulta lógico aceptar esta familia de tablas como el modelo de referencia.

Para cada una de las cuatro regiones, Coale y Demeny ofrecen 25 niveles de mortalidad, que oscilan, para el sexo femenino, entre los veinte y los ochenta años de esperanza de vida al nacimiento, con intervalos de 2,5 años. Con objeto de alcanzar una mayor aproximación, se han obtenido, mediante interpolación lineal, nueve tablas intermedias entre cada dos niveles de las tablas originarias. Ya que se trata de tablas abreviadas, la interpolación ha sido también empleada para calcular las tablas completas correspondientes. A partir de aquí se puede deducir el número de años vividos en cada edad por una generación teórica $\mathrm{y}$, por tanto, las respectivas poblaciones estacionarias asociadas. A continuación, calculamos las poblaciones estables correspondientes a la tasa de crecimiento seleccionada. Por último, y para cada una de estas poblaciones, determinamos los porcentajes de población que corresponden a cada grupo de edades del Censo de Floridablanca.

Hemos construido, de esta forma, un conjunto de poblaciones teóricas, y necesitamos un criterio que nos permita elegir la que mejor aproxima la población registrada. Para realizar esta elección, utilizaremos el test $G^{9}$. En nuestro caso, la estimación de la mortalidad que finalmente obtenemos se encuentra entre los niveles 3,5 (correspondiente a una tasa de crecimiento del 0,29 por 100) y 5 (correspondiente a una tasa de 0,59 por 100) de las tablas de Princeton. En base a estos resultados, y asumiendo que la morta-

\footnotetext{
9 F. Dopico (1987).
} 
lidad del otro sexo corresponde a los mismos niveles, podemos elaborar el cuadro 1.

\section{CUADRO 1}

Estimación de la esperanza de vida mínima y máxima.

España, segunda mitad del siglo XVIII

\begin{tabular}{|c|c|c|}
\hline & Minima & Máxima \\
\hline $\begin{array}{llllllll}\text { Mujeres } & \ldots & \ldots & \ldots & \ldots & \ldots & \ldots & \ldots \\
\text { Hombres } & \ldots & \ldots & \ldots & \ldots & \ldots & \ldots & \ldots \\
\text { Ambos sexos } & \ldots & \ldots & \ldots & \ldots & \ldots & \ldots\end{array}$ & $\begin{array}{l}26,3 \\
25,8 \\
26,0\end{array}$ & $\begin{array}{l}30,0 \\
29,3 \\
29,7\end{array}$ \\
\hline
\end{tabular}

Fuenre: Elaboración propia.

La debilidad de la estimación reside en las limitaciones de la teoría de las poblaciones parcialmente estables, y, sobre todo, en la incertidumbre acerca de la tasa de crecimiento. Sin embargo, el método permite establecer unos extremos claros, entre los que se movía la mortalidad española, que podrán ser aproximados en la medida que investigaciones posteriores permitan precisar la tasa de crecimiento. El cuadro 2 recoge la estimación de la esperanza de vida para diversos valores de aquella tasa.

\section{CUADRO 2}

Estimación de la esperanza de vida

al nacimiento, según los valores de la tasa

de crecimiento.

España, segunda mitad del siglo XVIII

\begin{tabular}{|c|c|}
\hline$r$ & $e_{o}$ \\
\hline $\begin{array}{l}0,35 \\
0,40 \\
0,45 \\
0,50 \\
0,55\end{array}$ & $\begin{array}{l}26,8 \\
27,2 \\
28,0 \\
28,5 \\
28,9\end{array}$ \\
\hline
\end{tabular}

FUENTE: Elaboración propia. 
Muy probablemente la esperanza de vida de los españoles en la segunda mitad del siglo xviri se encontraba entre los límites indicados en el cuadro 1, esto es, entre los 26,0 y los 29,7 años. Este intervalo comprende la estimación de M. Livi Bacci de 26,7 años, pero deja fuera los obtenidos por B. Cachinero (1985), que sitúa la esperanza de vida en 25,35 años para el período $1768-87$ y en 24,7 para 1787-97. El método de Preston-Bennet, adaptado por Cachinero, presenta la ventaja de no requerir ningún supuesto sobre la estabilidad de la población. Al estar, sin embargo, basado en las tasas específicas de crecimiento para cada grupo de edades, esta técnica es muy sensible a errores diferenciales en la cobertura de los dos censos; y sabemos que la mayoría de los investigadores otorgan un distinto grado de fiabilidad a los tres censos considerados.

\section{Los niveles de mortalidad regionales}

Para proceder al análisis regional, hemos agrupado la población del Censo de 1787 según las regiones y nacionalidades históricas. Los resultados obtenidos deben ser tomados como aproximaciones provisionales, válidas mientras los estudios de base regional no permitan establecer estimaciones más precisas. La metodología seguida tiene, no obstante, la ventaja de que sus resultados pueden ser rápidamente corregidos, en la medida en que estos últimos estudios permitan una mejor evaluación de los datos censales y una más adecuada estimación de las tasas de crecimiento respectivas. En nuestro caso, por ejemplo, la aparición del artículo de J. L. Hernández Marco y S. Piquero (1988) ha aconsejado cambiar la estimación para el País Vasco que habíamos hecho en una primera versión de este artículo.

Ya que no es probable la existencia de una emigración selectiva en los primeros años de edad, la relación de masculinidad en el primer grupo de edades del censo vendrá dada por la relación de masculinidad al nacimiento y las correspondientes probabilidades de muerte en estos años. Para los niveles de mortalidad presumiblemente existentes, esta relación de masculinidad (entre el nacimiento y los seis o siete años) debería situarse entre 1,02 y 1,04. Andalucía, Extremadura, Murcia y el País Valenciano superan claramente el límite superior, lo que nos lleva a pensar en la existencia de una subestimación femenina. Aun cuando las variaciones en la mortalidad por sexo a estas edades pueden ser importantes, y llegar a explicar relaciones de masculinidad aparentemente sorprendentes, la existencia de un subregistro relativo tampoco sería extraño si pensamos en la menor valoración de la mujer, en esos años, a efectos fiscales, laborales y militares. Por el contrario, en Cataluña el análisis de lós censos de Floridablanca y Godoy hacen pensar en una 
subestimación masculina. Para la mayoría de los resultados obtenidos en este trabajo, esta subestimación sería irrelevante si fuese similar en todos los grupos de edad, pero alteraría los mismos si sólo se produjera en algunos de ellos (por ejemplo, en los primeros años de vida).

La mayor dificultad reside, sin embargo, en la estimación de la tasa de crecimiento, que asimilaremos a la tasa de crecimiento intrínseca de la población. Usaremos para este fin las series de bautizados disponibles para las diferentes regiones y nacionalidades históricas. Desde el punto de vista teórico, nada hay que objetar, pues la constancia de la tasa bruta de nacimiento es una propiedad de las poblaciones casi malthusianas. En la práctica, y pese a las oscilaciones a corto plazo en la natalidad, propias de las sociedades de antiguo régimen demográfico, los datos de nacimientos pueden ser utilizados como indicadores aproximados de la evolución a largo plazo de la población si los cambios en la fecundidad, tal como hemos supuesto, no son relevantes. El problema principal consistirá, por consiguiente, en construir series representativas. El conjunto de las parroquias tomadas como muestra debe representar una proporción constante del total regional a lo largo del período examinado. Muchas veces no es posible verificar esta condición, y en las series consideradas hay probablemente varias que no la cumplen. El caso de Extremadura, recogido en el cuadro 3, es una prueba de las divergencias que pueden darse cuando se toman dos muestras diferentes. El error en la estimación de la tasa de crecimiento puede repercutir de forma importante en los resultados finales, por lo que de nuevo éstos se verán encuadrados entre un límite inferior y otro superior. Afortunadamente, como ya hemos señalado, esta fuente de errores podrá ser reducida en el futuro mediante la construcción de series más representativas.

El cuadro 3 muestra las tasas de crecimiento de los bautismos para dos período, 1700-1790 y 1740-1790. Hemos utilizado las series de J. Nadal para Andalucía, Castilla la Vieja, Castilla la Nueva, Cataluña y Galicia. Para Extremadura, usaremos la media de las estimaciones de Nadal y Rodríguez Sánchez. Los datos de base del País Valenciano proceden de J. M. Pérez García y M. Ardit. Con respecto a Baleares, tomaremos una media ponderada de las tasas que se deducen de las parroquias estudiadas por I. Moll, A. Segura y J. Suau para Mallorca, y Vidal Bendito para Menorca. No consideraremos los datos de León, a tenor de la disparidad de las tasas de crecimiento obtenidas. Para el País Vasco, partiremos de la tasa de 0,41 por 100, propuesta por J. L. Hernández Marco y S. Piquero (1988) en el artículo anteriormente mencionado, sobre la que hemos supuesto una posible oscilación del 10 por 100. La tasa asignada a Asturias es de 0,45 por 100 , que se deduce de los datos que para el siglo xvili proporciona Carmen M. Sanzo (1982), con la correspondiente banda de oscilación. Para León, 
Aragón, Navarra y Murcia hemos tomado unos límites iguales a los que fijaremos para el conjunto de la población española (entre el 0,41 y el 0,51 por 100). Estas estimaciones son realizadas para poder completar, a efectos comparativos y dentro de unas hipótesis razonables, la totalidad de la España peninsular.

\section{CUADRO 3}

Tasas de crecimiento de las regiones bistóricas

(En tanto por 100)

\begin{tabular}{|c|c|c|}
\hline & $1700-1790$ & $1740-1790$ \\
\hline 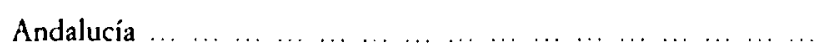 & 0,53 & 0,43 \\
\hline 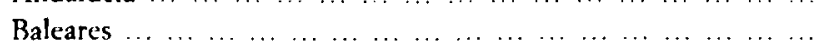 & 0,26 & 0,22 \\
\hline 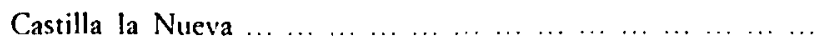 & 0,30 & 0,51 \\
\hline 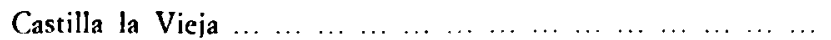 & 0,37 & 0,46 \\
\hline $\begin{array}{lllllllllllllllll}\text { Cataluña } & \ldots & \ldots & \ldots & \ldots & \ldots & \ldots & \ldots & \ldots & \ldots & \ldots & \ldots & \ldots & \ldots & \ldots & \ldots & \ldots\end{array}$ & 0,57 & 0,85 \\
\hline $\begin{array}{lllllllllllll}\text { Extremadura }(\text { Nadal }) & \ldots & \ldots & \ldots & \ldots & \ldots & \ldots & \ldots & \ldots & \ldots & \ldots & \ldots & \ldots\end{array}$ & 0,34 & 0.22 \\
\hline 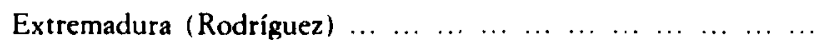 & 0,68 & 0,59 \\
\hline $\begin{array}{llllllllllllllllll}\text { Galicia } & \ldots & \ldots & \ldots & \ldots & \ldots & \ldots & \ldots & \ldots & \ldots & \ldots & \ldots & \ldots & \ldots & \ldots & \ldots\end{array}$ & 0,37 & 0,47 \\
\hline $\begin{array}{llllllllllllllllll}\text { León } & \ldots & \ldots & \ldots & \ldots & \ldots & \ldots & \ldots & \ldots & \ldots & \ldots & \ldots & \ldots & \ldots & \ldots & \ldots & \ldots\end{array}$ & 0,65 & 0,18 \\
\hline $\begin{array}{llllllllllllll}\text { País Valenciano } & \ldots & \ldots & \ldots & \ldots & \ldots & \ldots & \ldots & \ldots & \ldots & \ldots & \ldots & \ldots & \ldots\end{array}$ & 0,82 & 0,66 \\
\hline
\end{tabular}

Fuentes: Elaboración propia a partir de J. Nadal (1974); A. Rodríguez Sánchez (1988); J. M. Pérez García y M. Ardit (1988); I. Moll, A. Segura y J. Suau (1983), y T. Vidal y J. Gomila (1986).

Para cada región tenemos así estimadas dos tasas de crecimiento, cada una de las cuales, en unión de la composición por edades de su población femenina, nos proporciona un nivel de mortalidad. La media aritmética de las esperanzas de vida asociadas a estos niveles constituirá la estimación seleccionada para cada región. El cuadro 4 recoge los resultados, referidos al conjunto de los dos sexos, que se obtienen de esta forma. 


\section{CUADRO 4}

Esperanza de vida al nacimiento,

en las regiones bistóricas

(segunda mitad del siglo XVIII)

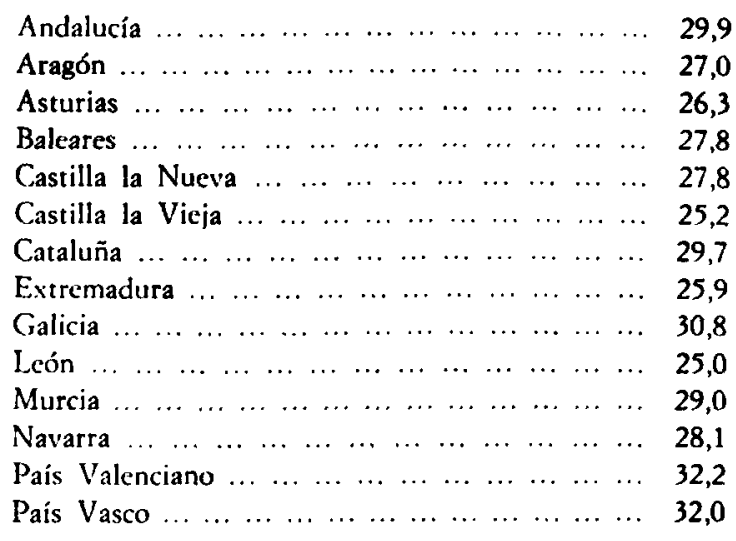

Fuente: Elaboración propia.

En la sección anterior establecíamos unos límites de crecimiento, para el conjunto de la población española, entre el 0,29 y el 0,59 por 100 . Podemos ahora reducir este intervalo utilizando las tasas de crecimiento

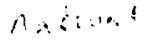
reproducidas en el cuadro 3, ponderadas por la población respectiva en 1787 . Esto conduce a una tasa de crecimiento de 0,47 por 100 entre 1700 y 1790 , y de 0,45 por 100 entre 1740 y 1790 . Al aplicar la metodología anterior, la esperanza de vida se sitúa en 28,4 años para las mujeres y en 28,1 años para ambos sexos ${ }^{10}$.

${ }^{10}$ Parece admisible suponcr que el margen de error en la estimación de la tasa de crecimiento no supera el 10 por 100 . En este caso, la población española estaría creciendo, en las décadas anteriores al censo de Floridablanca, a un ritmo situado entre el 0,41 y el 0,51 por 100 . Si esto es así, de acuerdo con la metodología que hemos desarrollado, la esperanza de vida se sitúa entre 27,7 y 28,9 años para las mujeres, y entre 27,4 y 28,6 años para ambos sexos. 


\section{MAPA 1}

Esperanza de vida en las Regiones Históricas (segunda mitad del siglo XVIII)

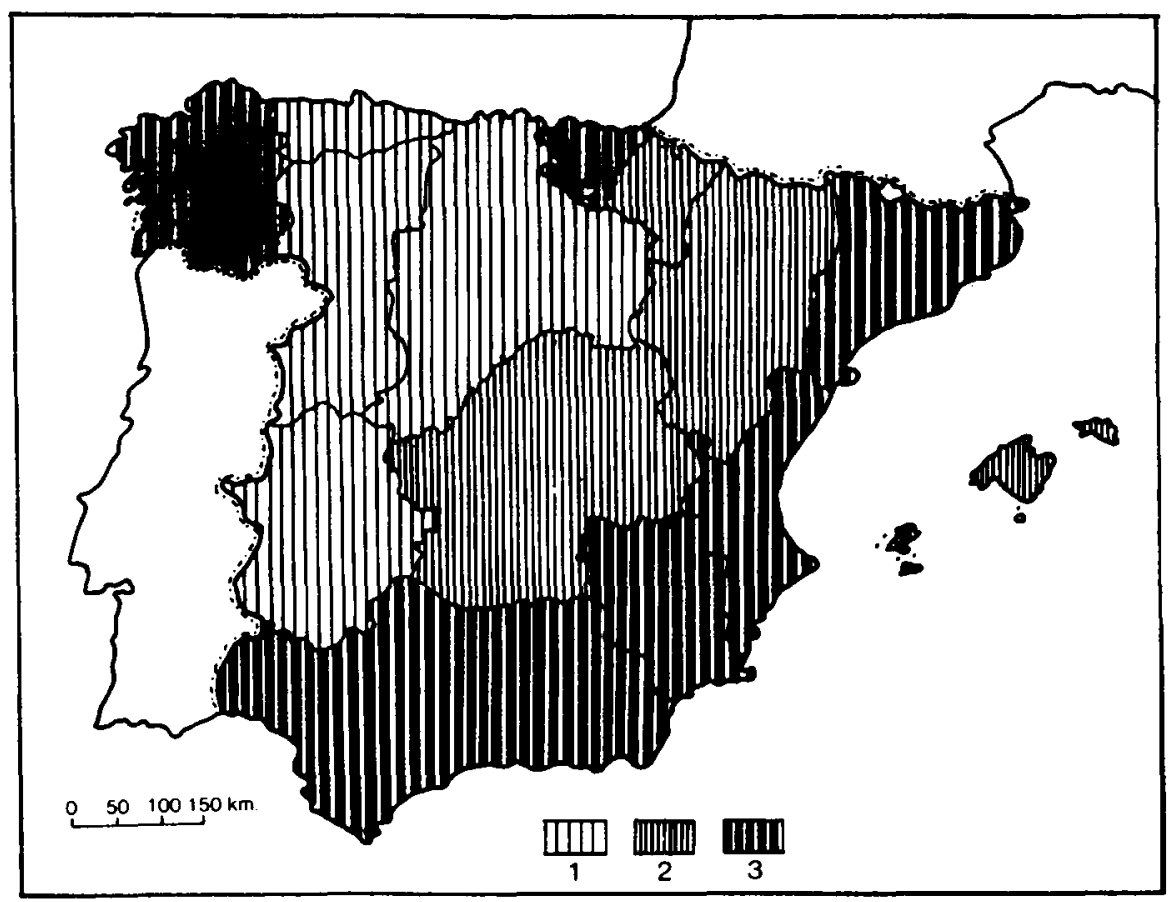

$1=e_{0}<26,5$.

$2=26,5<e_{0}<28,5$.

$3=e_{0}>28,5$.

\section{La fecundidad de la población española}

Conocido el nivel de mortalidad y la tasa de crecimiento, el cálculo de la tasa bruta de natalidad (TBN) es inmediato, aplicando las relaciones establecidas en la teoría de las poblaciones estables. Para un crecimiento anual de 0,46 por 100 , la TBN intrínseca de la población femenina es de 40,1 por 1.000 ".

"Para los límites de la tasa de crecimiento anteriormente fijados, la TBN intrínseca de población femenina correspondiente al 0,41 por 100 sería de 40,4 por 1.000 , y la asociada a un crecimiento de 0,51 por 100 se situaría en 39,9 por 1.000 . 
Para cada tasa de crecimiento elegida conocemos la TBN y, por consiguiente, el número total de nacimientos. No nos queda determinado, sin embargo, el calendario de la fecundidad, pues dos poblaciones estables con la misma estructura de edades y la misma tasa de natalidad pueden presentar diferencias en las edades en que las madres tienen a sus hijos. Es preciso, por tanto, incorporar alguna hipótesis adicional que nos permita estimar la edad media a la maternidad.

Existen fuertes indicios de que en la España del siglo xvill no se practicaba, de forma significativa, el control consciente de los nacimientos. Es razonable, pues, seleccionar algún modelo de fecundidad que se corresponda con el llamado régimen de fecundidad natural. Por nuestra parte, adaptaremos la pauta de fecundidad natural elaborada por Coale y Trussell ${ }^{12}$ a los grupos de edades del censo de Floridablanca, empleando para su ponderación el censo de 1887, el primero utilizable a estos efectos. El cálculo de la edad media a la maternidad se realiza a partir del cuadro 5 . La columna 2 recoge el patrón de fecundidad antes descrito. Dividiendo la suma de la columna 5 por la de la columna 3 , obtenemos una edad media al matrimonio de 31,5 años.

\section{CUADRO 5}

Cálculo edad media a la maternidad segín un patrón de fecundidad natural. España, 1787

\begin{tabular}{|c|c|c|c|c|c|}
\hline Edades & $\begin{array}{l}\text { Propor- } \\
\text { ción } \\
\text { casadas } \\
\text { (1) }\end{array}$ & $\begin{array}{l}\text { Patrón } \\
\text { tecundidad } \\
\text { natural } \\
\text { (2) }\end{array}$ & $\begin{array}{c}\text { (1) } \times(2) \\
(3)\end{array}$ & $\begin{array}{l}\text { Edad } \\
\text { central } \\
\text { (4) }\end{array}$ & $\begin{array}{c}(3) \times(4) \\
(5)\end{array}$ \\
\hline $\begin{array}{llllll}16-24 & \ldots & \ldots & \ldots & \ldots & \ldots \\
25.39 & \ldots & \ldots & \ldots & \ldots & \ldots \\
40.49 & \ldots & \ldots & \ldots & \ldots & \ldots\end{array}$ & $\begin{array}{l}0,263 \\
0,753 \\
0,724\end{array}$ & $\begin{array}{l}1,000 \\
0,852 \\
0,229\end{array}$ & $\begin{array}{l}0,263 \\
0,641 \\
0,166\end{array}$ & $\begin{array}{l}20,5 \\
32,5 \\
45,0\end{array}$ & $\begin{array}{r}5,386 \\
20,839 \\
7,457\end{array}$ \\
\hline Total ... ...... & & & 1,070 & & 33,683 \\
\hline
\end{tabular}

Fdad media maternidad: 31,489

Fuente: Elaboración propia.

${ }^{12}$ A. J. Coale y J. Trussell (1974 y 1975); J. Trussell (1979). 
A partir de los datos anteriores, se puede calcular la tasa bruta de reproducción (TBR), que para el conjunto de la población española queda establecida en 2,78 hijas por mujer ${ }^{13}$.

Para cada tasa de crecimiento de la población, conocemos el número de nacimientos femeninos de la población femenina $y$, por consiguiente, multiplicando por 2,05 (suponiendo una relación de masculinidad al nacimiento de 1,05), obtenemos el número de nacimientos totales. Conocemos también el número de mujeres casadas en edad fértil. Para calcular la tasa global de fecundidad matrimonial (TGFM) sólo necesitamos saber el porcentaje de los nacimientos totales que corresponden a estas mujeres. Livi Bacci tomó la misma tasa que para los años 1858 a 1862 , pero hay indicios de que en España, como en otros países de Europa occidental, la ilegitimidad se incrementó a lo largo de la primera mitad del siglo xIX. Un caso límite lo constituyó, sin duda, Galicia, donde el descenso de las posibilidades de contraer matrimonio para la mujer, provocado por una intensa emigración masculina, es el factor fundamental que explica el paso de una tasa de ilegitimidad de 41 por 1.000 en $1760-90$ a 138 por 1.000 en $1861-70^{14}$. En las estimaciones que siguen; seleccionaremos la media aritmética resultante de dos alternativas extremas; en la primera, supondremos que la tasa de ilegitimidad no varía entre la segunda mitad del siglo xvin y el período 1861-70; la segunda, que el porcentaje de ilegítimos se situaba entonces en el 30 por 100 de este último período, siguiendo la misma tendencia que Galicia.

En el período 1861.70 nacieron en España 56 ilegítimos por cada 1.000 nacidos vivos. De haberse mantenido esta proporción constante desde la segunda mitad del siglo xviII, la tasa global de fecundidad matrimonial (TGFM) se situaria en 263,4 nacimientos legítimos por cada 1.000 mujeres casadas entre dieciséis y cuarenta y nueve años. Pero si consideramos que la ilegitimidad era considerablemente menor (tan sólo del 17 por 1.000), la TGFM alcanza el 274,2. Como lo más probable es que la ilegitimidad haya aumentado en una proporción menor que la gallega, la TGFM podría situarse en torno a la media de las estimaciones anteriores, es decir, en unos 268,8 hijos por 1.000 mujeres casadas y en edad fértil.

A partir de los datos anteriores, el cálculo del índice $I g$ de fecundidad matrimonial no ofrece mayor dificultad. Por una parte, conocemos el número de nacimientos legítimos de las mujeres en edad fértil. Por otra parte, pode-

13 Los límites para la TBR se sitúan ahora entre 2,80 hijas por mujer para una tasa de crecimiento de 0,41 por 100 , y 2,77 hijas por mujer para un crecimiento acumulativo anual de 0,51 por 100 .

"M. X. Rodriguez Galdo. 
mos calcular el número «teórico» de hijos que tendrían esas mismas mujeres si su comportamiento fuese igual al de las Hutteritas. Empleando las mismas tasas de fecundidad por edad para estas últimas que Livi Bacci, llegamos a un valor promedio para el índice de Princeton de $0,723^{15}$.

\section{Los niveles de fecundidad regional}

La metodología desarrollada en la sección anterior puede aplicarse en sur totalidad a las poblaciones de las regiones históricas, a partir de los resultados de la sección 3, las estimaciones de la edad media a la maternidad que se ofrecen en el cuadro $6, y$ los datos sobre ilegitimidad del cuadro 7.

\section{CUADRO 6}

\section{Edad media a la maternidad} en las regiones bistóricas

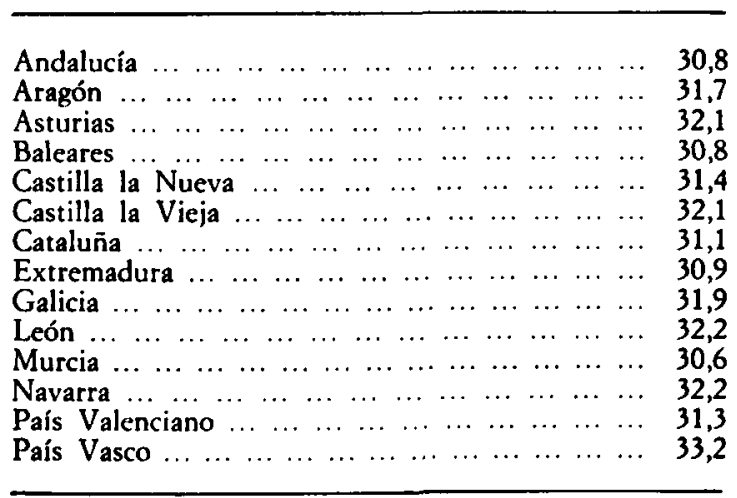

FUENTE: Elaboración propia.

15 En este caso se pueden ofrecer cuatro estimaciones alternativas de acuerdo con las hipótesis formuladas para la tasa de crecimiento y la ilegitimidad. Para un crecimiento del 0,41 por 100 , el indice $I g$ valdrá 0,753 si la ilegitimidad es del 17 por 100 , y 0,742 si es del 56 por 100. Para una tasa de crecimiento del 0,51 por 100 , los valores anteriores serán 0,713 y 0,704 , respectivamente. 


\section{CUADRO 7}

\section{Tasas de ilegitimidad (1861-70)}

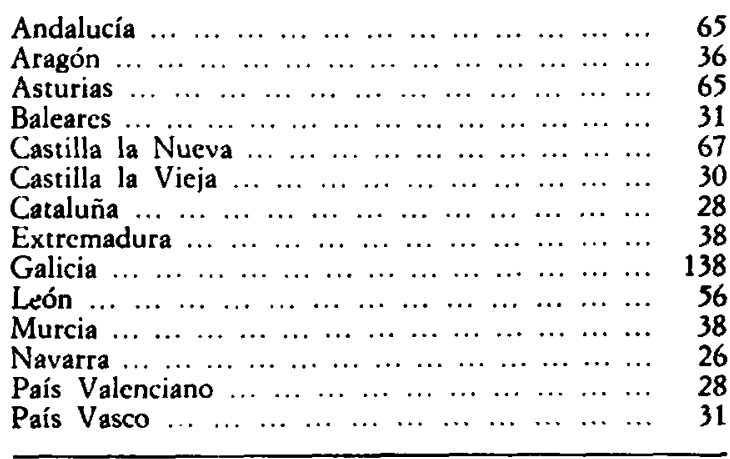

FUENTE: Elaboración propia.

Los resultados se sintetizan en los cuadros 8 a 10 . El cuadro 8 recoge las estimaciones de la tasa bruta de reproducción para los distintos espacios regionales. El cuadro 9 muestra los valores de la tasa global de fecundidad matrimonial. Finalmente, el cuadro 10 presenta los valores promedio de Ig.

\section{CUADRO 8}

Tasa brula de reproducción en las regiones bistóricas

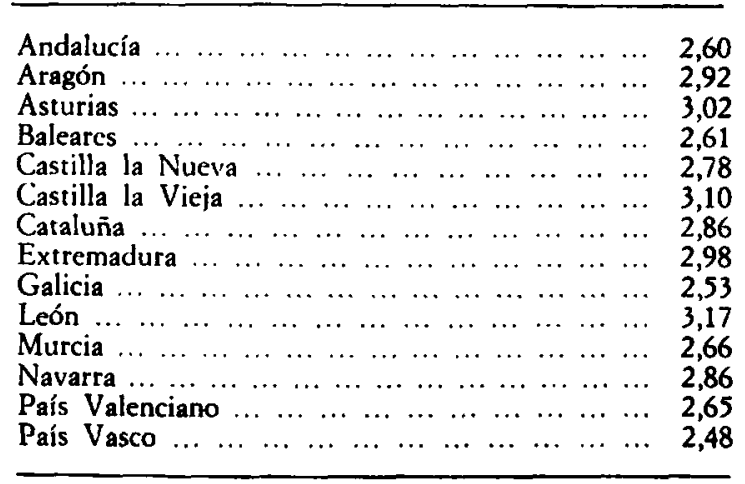

Fuente: Elaboración propia. 


\section{CUADRO 9}

\section{Tasa global de fecundidad matrimonial en las regiones bistóricas}

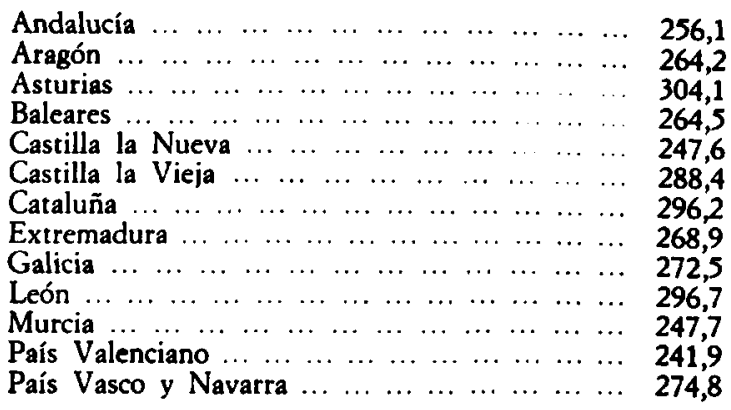

FUENTE: Elaboración propia.

CUADRO 10

Indice de fecundidad matrimonial en las regiones bistóricas

\begin{tabular}{|c|c|}
\hline 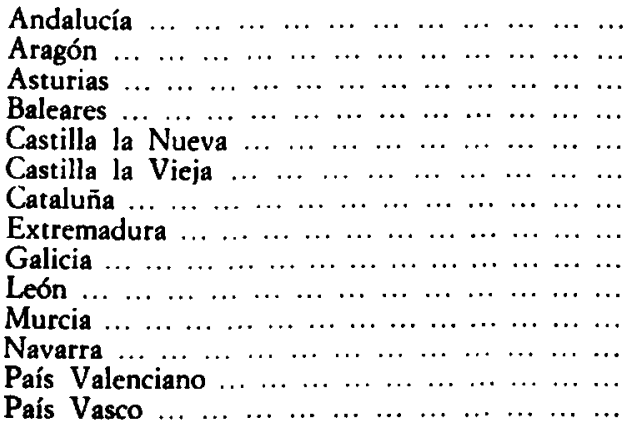 & $\begin{array}{l}0,716 \\
0,844 \\
0,702 \\
0,653 \\
0,779 \\
0,819 \\
0,702 \\
0,757 \\
0,807 \\
0,656 \\
0,769 \\
0,644 \\
0,762\end{array}$ \\
\hline
\end{tabular}

FuENTE: Elaboración propia. 


\section{Evaluación de los resultados}

De acuerdo con las estimaciones anteriores, España tenía, en la segunda mitad del siglo xvirr, una esperanza de vida al nacimiento en torno a los veintiocho años, muy próxima a la alcanzada por Francia en las décadas anteriores a la Revolución Francesa ${ }^{10}$, e inferior a la de Inglaterra ${ }^{17}$ y a la de los países escandinavos ${ }^{18}$. Su tasa bruta de reproducción era de casi 2,8 hijas por mujer, más elevada que la de Francia ${ }^{19}$ o Suecia y ligeramente superior a la de Inglaterra en el último tercio del siglo xviII, si bien menor de los valores alcanzados por ésta en las primeras décadas del siglo XIX. Unos resultados que, en conjunto, tienden a acercar la población española a un modelo de alta presión demográfica, que vendría caracterizado sobre todo por una nupcialidad más intensa y una mortalidad más elevada que la de la Europa Noroccidental, pues el índice $\mathrm{Ig}$ de 0,72 nos muestra una fecundidad matrimonial más bien moderada dentro del antiguo régimen demográfico. Esta situación se habría mantenido hasta bien avanzado el siglo xIx, ya que en la década de 1860 España había ganado menos de dos años en la duración media de la vida con respecto al siglo anterior ${ }^{20} \mathrm{y}$ hay indicios de que el descenso de la fecundidad sólo se había iniciado en unas pocas zonas de su territorio.

Las cifras a nivel español esconden, como es habitual, importantes contrastes regionales. El mapa 1 muestra las expresivas disparidades existentes en el nivel de mortalidad. En líneas generales, responden a lo que sabíamos hasta ahora sobre la superioridad de la periferia frente al interior peninsular, que ya hace tiempo señalaron investigadores como $\mathrm{E}$. Fernández de Pinedo (1980) y V. Pérez Moreda (1980). El cuadro 11 compara la esperanza de vida en la segunda mitad del siglo xvin con la correspondiente a la década de 1860. Los cambios más significativos se dan en Asturias, Baleares y el País Valenciano. Baleares fue un país pionero en el descenso de la fecundidad y la mortalidad infantil, y los datos parecen configurar ahora una excelente mejora en la mortalidad general a lo largo del siglo xIX El aumento de la mortalidad valenciana puede estar justificada por circunstancias excepcionales, y particularmente por la severidad del cólera de 1865. Estudios locales y comarcales deberán arrojar más luz sobre el país asturiano para poder precisar si el importante descenso registrado refleja la realidad o es consecuencia de la deficiente calidad de los datos. En las demás regiones

16 Y. Blayo (1975).

"E. A. Wrigley y R. S. Schofield (1981).

"W. R. Lee (1979); T. Bengtsson, G. Fridlizius y R. Ohlsson (1981).

19 E. A. Wrigley (1985).

* F. Dopico (1987). 
los cambios son moderados, y se sigue manteniendo una clara superioridad de las regiones costeras. La proximidad entre los valores de la segunda mitad del siglo xvili y los de la segunda mitad del siglo xix no implica que el nivel de la mortalidad se haya mantenido estable. A pesar de trabajos tan notables como el de V. Pérez Moreda (1985), la primera mitad del siglo xIX sigue constituyendo desde el punto de vista demográfico, como desde otras facetas económicas y sociales, un período muy poco conocido para que podamos establecer hipótesis fiables sobre el comportamiento de la mortalidad.

\section{CUADRO 11}

\section{Evolución de la esperanza de vida en las regiones bistóricas}

\begin{tabular}{|c|c|c|c|}
\hline & S. XVIII & $1863-70$ & Variación \\
\hline 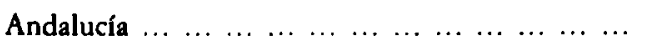 & 29,9 & 30,6 & 0,7 \\
\hline 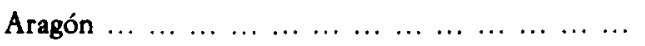 & 27,0 & 25,5 & $-1,5$ \\
\hline $\begin{array}{llllllllllll}\text { Asturias } & \ldots & \ldots & \ldots & \ldots & \ldots & \ldots & \ldots & \ldots & \ldots & \ldots & \ldots\end{array}$ & 26,3 & 37,2 & 10,9 \\
\hline $\begin{array}{lllllllllllll}\text { Baleares } & \ldots & \ldots & \ldots & \ldots & \ldots & \ldots & \ldots & \ldots & \ldots & \ldots & \ldots & \ldots\end{array}$ & 27,8 & 41,7 & 14,0 \\
\hline $\begin{array}{llllllllll}\text { Castilla la Nueva } & \ldots & \ldots & \ldots & \ldots & \ldots & \ldots & \ldots & \ldots & \ldots\end{array}$ & 27,8 & 26,7 & $-1,1$ \\
\hline $\begin{array}{lllllllllll}\text { Castilla la Vieja } & \ldots & \ldots & \ldots & \ldots & \ldots & \ldots & \ldots & \ldots & \ldots & \ldots\end{array}$ & 25,2 & 26,7 & 1,5 \\
\hline $\begin{array}{lllllllllllll}\text { Cataluña } & \ldots & \ldots & \ldots & \ldots & \ldots & \ldots & \ldots & \ldots & \ldots & \ldots & \ldots & \ldots\end{array}$ & 29,7 & 29,6 & $-0,1$ \\
\hline 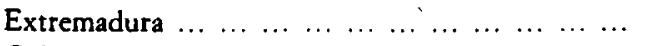 & 25,9 & 27,4 & 1,5 \\
\hline 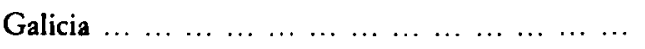 & 30,8 & 34,8 & 4,0 \\
\hline $\begin{array}{llllllllllllll}\text { León } & \ldots & \ldots & \ldots & \ldots & \ldots & \ldots & \ldots & \ldots & \ldots & \ldots & \ldots & \ldots\end{array}$ & 25,0 & 25,9 & 0,9 \\
\hline $\begin{array}{lllllllllllll}\text { Murcia } & \ldots & \ldots & \ldots & \ldots & \ldots & \ldots & \ldots & \ldots & \ldots & \ldots & \ldots & \ldots\end{array}$ & 29,0 & 31,4 & 2,4 \\
\hline $\begin{array}{lllllllllllll}\text { Navarra } & \ldots & \ldots & \ldots & \ldots & \ldots & \ldots & \ldots & \ldots & \ldots & \ldots & \ldots & \ldots\end{array}$ & 28,1 & 29,6 & 1,5 \\
\hline $\begin{array}{llllllllll}\text { País Valenciano } & \ldots & \ldots & \ldots & \ldots & \ldots & \ldots & \ldots & \ldots & \ldots\end{array}$ & 32,2 & 29,0 & $-3,2$ \\
\hline $\begin{array}{llllllllllll}\text { País Vasco } & \ldots & \ldots & \ldots & \ldots & \ldots & \ldots & \ldots & \ldots & \ldots & \ldots & \ldots\end{array}$ & 32,0 & 33,9 & 1,9 \\
\hline
\end{tabular}

Fuentes: Cuadro 4 y F. Dopico (1987).

La edad media al matrimonio en la mujer parece ser una variable rele vante a la hora de explicar las diferencias en la fecundidad matrimonial, ya que existe una asociación bastante clara entre una nupcialidad más tardía y un valor mayor del índice de Princeton. Como queda reflejado en los mapas 2 


\section{MAPA 2}

Edad media de acceso al matrimonio (mujeres), en las Regiones Históricas (segunda mitad del siglo XVIII)

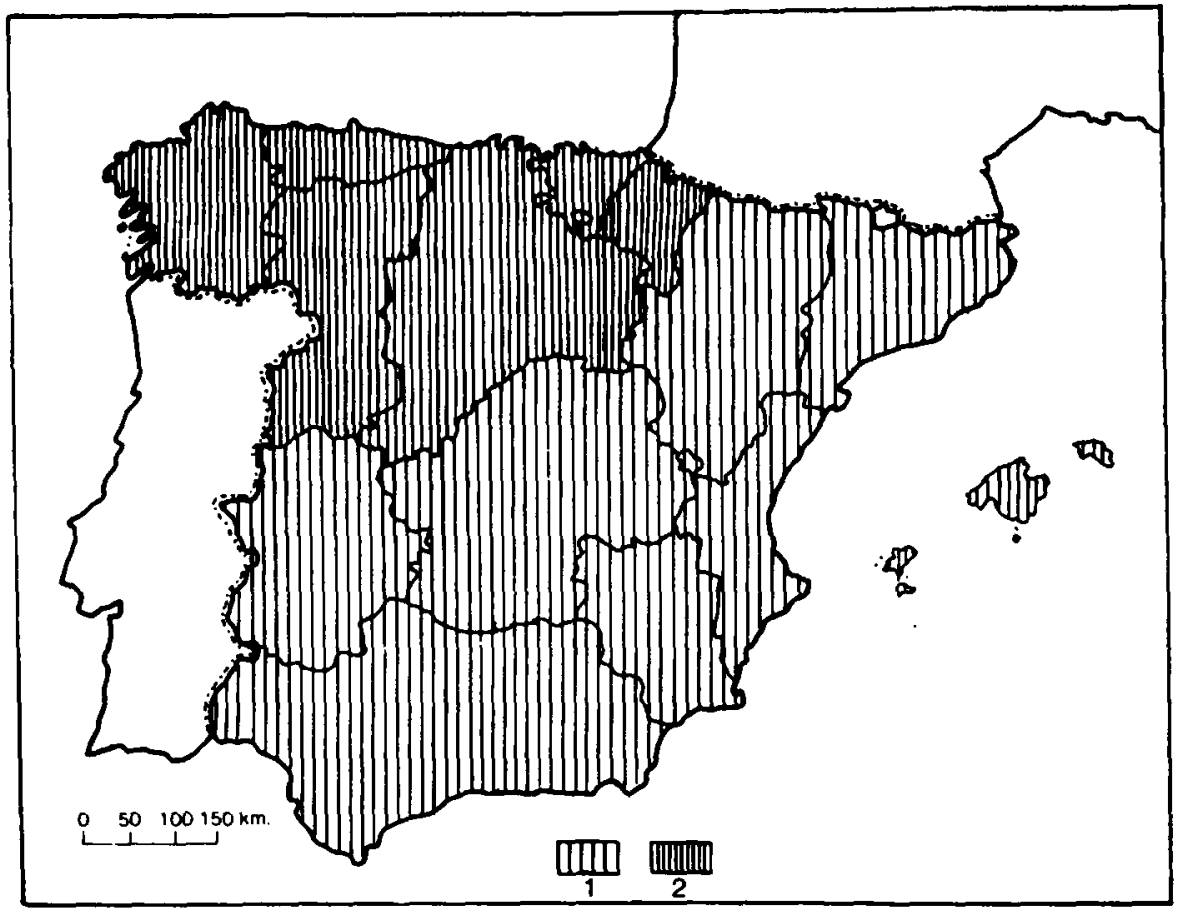

$1=\mathrm{EAM}<23,5$.

$2=\mathrm{EAM}>23,5$.

y 3 , todas las regiones con una edad media al primer matrimonio superior a la española $(23,5$ años) tienen un índice $I g$ asimismo superior a la media. $\mathrm{Y}$ todas las regiones con una nupcialidad femenina relativamente precoz poseen, con una sola excepción, un índice $I g$ inferior a la media española. La excepción es Cataluña, que tiene uno de los valores más elevados de fecundidad legítima y una edad media al primer matrimonio femenino de 23,2 años ${ }^{21}$.

"R. Rowland (1988). 


\section{MAPA 3}

Indice Ig de fecundidad matrimonial, en las Regiones Históricas (segunda milad del siglo XVIII)

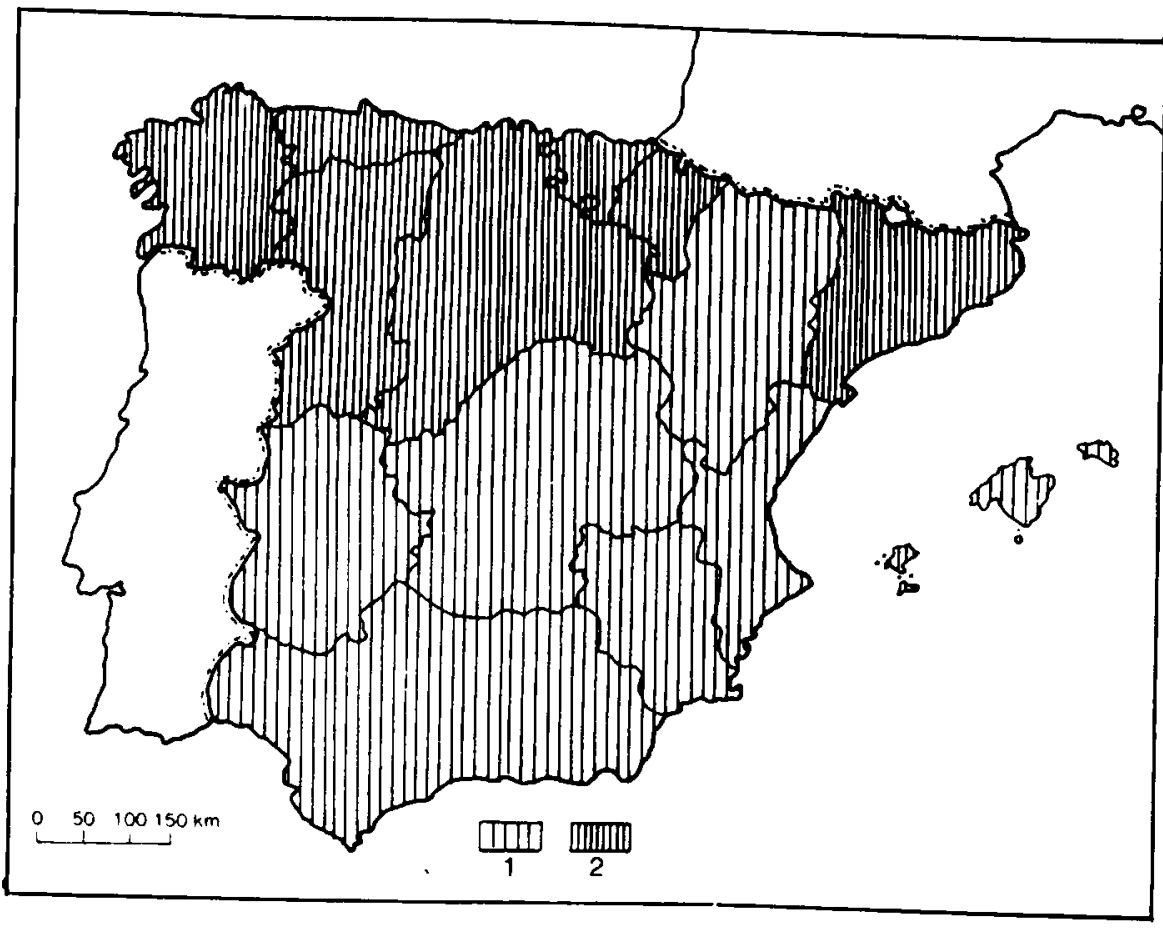

$1=I_{g} \leqslant 0,72$.

$2=I g>0,72$

El cuadro 8 y el mapa número 4 muestran los valores de la tasa bruta de reproducción. La mayoría de las regiones costeras tienen una suave fecundidad general, aunque por diferentes motivos. La alta edad media al matrimonio, junto con una considerable soltería definitiva, explican las moderadas tasas del País Vasco y de Galicia. El elevado celibato de las mujeres de Andalucía y Baleares compensa un matrimonio más joven y, juntamente con una fecundidad legítima algo menor que la media española, determinan una TBR alrededor de 2,6 hijas por mujer. Los bajos índices de fecundidad matrimonial, dentro de un régimen de fecundidad «natural», son precisamente los causantes de que las TBR del País Valenciano y de Murcia se man- 
MAPA 4

Tasa bruto de reproducción, en las Regiones Históricas (segunda mitad del siglo XVIII)

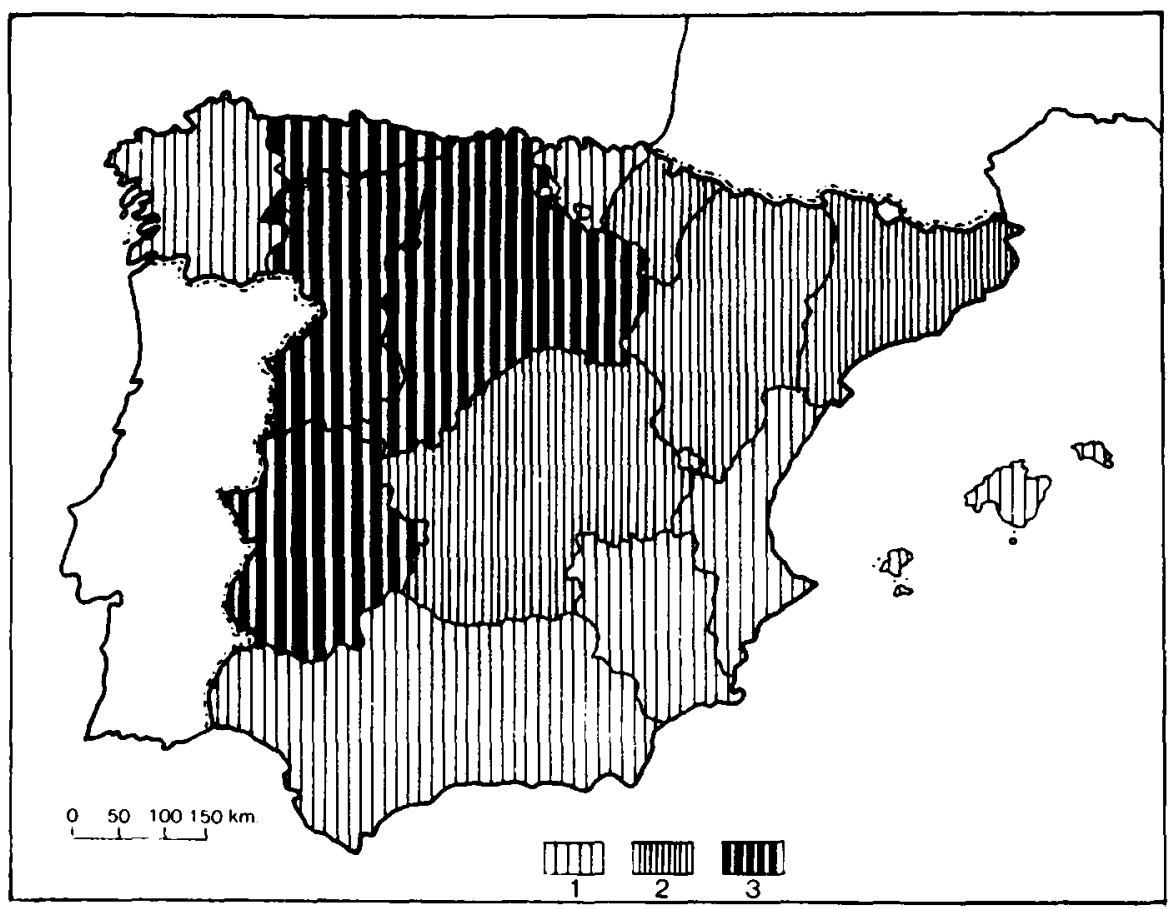

$1=\mathrm{TBR}<2,70$.

$2=2,70<\mathrm{TBR}<2,95$.

$3=\mathrm{TBR}>2,95$.

tengan en niveles relativamente comedidos. Un segundo grupo, con TBR intermedias, en torno a 2,8 ó 2,9 , está constituido por cuatro regiones del Nordeste y el interior peninsular: Castilla la Nueva, Cataluña, Navarra y Aragón. Por último, las regiones de elevada fecundidad constituyen una franja situada en el Oeste y Norte peninsular, desde Extremadura hasta Asturias, en esta última debido a una estimable fecundidad matrimonial.

El trabajo de Massimo Livi Bacci (1968) constituye una importante aportación metodológica en los estudios de demografía histórica, convirtiéndose desde su publicación en referencia obligada para el análisis de los comienzos 
de la transición demográfica en España. Recibió asimismo algunas críticas, entre las que sobresale la suscrita por A. Eiras Roel (1982). Eiras realizó una dura descalificación de la metodología empleada, llegando a poner en cuestión la viabilidad de la aplicación de la teoría de las poblaciones estables a los estudios históricos:

"Las conclusiones de esta crítica no afectan solamente al método de Livi Bacci: afectan en general al empleo de la técnica de poblaciones estables a las poblaciones de régimen antiguo y conocidas a partir de censos preestadísticos. Es una pena, porque los análisis de poblaciones estables tienen la ventaja de ser eficientes, rápidos, espectaculares, y sobre todo de liberar del penoso trabajo de archivo en la búsqueda y vaciado de las fuentes propiamente demográficas; liberarían al historiador de la dura y penosa ley de la necesidad de acumular multitud de estudios demográficos locales, comarcales o regionales para aproximarse a las tendencias y evolución de la población. Pero son teóricamente insostenibles y afectados de vicios de origen, como el otorgar confianza matemática a recuentos oficiales poco perfectos $y$, sobre todo, considerar estables en la larga duración poblaciones que no lo son.»

Sin embargo, veinte años después del artículo del demógrafo italiano nadie ha ofrecido una alternativa a sus evaluaciones, y los trabajos de tipo local o comarcal son totalmente insuficientes para of recer un mapa regional representativo de la segunda mitad del siglo XVIII ${ }^{22}$. Las variaciones en la distribución por edades según los censos de Aranda, Floridablanca y Godoy son menores a las de censos de países subdesarrollados a los que se ha aplicado con éxito la teoría de las poblaciones estables y poblaciones derivadas de éstas. Sabemos que las crisis de mortalidad eran frecuentes en la España del siglo xviII, especialmente en el interior de la Península, pero sus efectos no parecen haber sido tan intensos ni discriminatorios con los diferentes grupos de edades para alterar sustancialmente la composición relativa de estos últimos. Por otra parte, si los cambios en la fecundidad hubiesen sido importantes se habrían transmitido rápidamente a la estructura de edades, por lo que debemos admitir una cierta constancia de la fecundidad, lo que, por supuesto, no es incompatible con las tradicionales fluctuaciones a corto plazo a nivel local.

Nos parece, por consiguiente, que Livi Bacci estaba acertado al aplicar las técnicas de poblaciones estables y su trabajo mereció ciertamente la

${ }^{22}$ R. Rowland (s. f.). 
repercusión que tuvo. Una parte de sus conclusiones debían ser, sin embargo, matizadas. Los pocos estudios de calidad realizados con la técnica de reconstrucción de familias parecen avalar más que contradecir los resultados a que conduce el ejercicio metodológico aquí propuesto. Aun así, debemos recordar que, en rigor, no existe ninguna población estable, es decir, que mantenga invariable su fecundidad y su mortalidad. Las poblaciones estables son modelos matemáticos que pueden aproximar más o menos satisfactoriamétodo en sí mismo es muy, posiblemente, inferior al emanado de la calidad de error en nuestras estimaciones. Pero el error que pueda derivarse del método en sí mismo es muy posiblemente inferior al emanado de la calidad de los datos manejados. Ya vimos cómo una modificación en la tasa de crecimiento de la población puede alterar las estimaciones efectuadas, especialmente en lo que se refiere al nivel de mortalidad. Afortunadamente, este problema puede ser subsanado en la medida en que los estudios regionales nos vayan ofreciendo índices más representativos. Más grave serían, por supuesto, los errores en la distribución por edades, que, de demostrarse, podrían alterar seriamente los resultados.

Si comparamos nuestros resultados con los de Livi Bacci, las diferencias no son espectaculares, ya que algunas de las rectificaciones tienden a compensarse entre sí, pero sí suficientes para alterar sustancialmente algunas de sus conclusiones. "Hacia 1887 , la TFM y el $I g$ se sitúan del 17 al 20 por 100 por debajo de los valores de 1768 , afirma Livi Bacci (1978), refiriéndose al conjunto de la población española. Si comparamos, en cambio, el índice Ig que hemos obtenido para 1787 con las estimaciones del grupo de investigadores de Princeton ${ }^{23}$, obtenemos una reducción de 0,72 a 0,65 , es decir, del 10 por 100 . Livi Bacci encontraba una importante disminución de la fecundidad en las regiones pertenecientes a la antigua corona de Aragón y también, con anterioridad a 1860 , en el Norte peninsular. Nuestras estimaciones permiten precisar que, antes de esa fecha, tal descenso se circunscribió fundamentalmente a Cataluña y Baleares. El cuadro 16 muestra que la disminución del índice $I g$ fue muy grande en Cataluña (35 por 100) y apreciable en Baleares (17 por 100). León y Navarra sufren también una reducción superior al 10 por 100 , pero, en estas regiones, el Ig sube después de 1887 , y se mantiene en valores elevados durante el primer tercio del siglo actual, lo que hace pensar en la inexistencia, con anterioridad a aquella fecha, de un control generalizado de los nacimientos. Todas las demás regiones experimentan, como puede apreciarse, un descenso muy moderado de la fecundidad matrimonial.

${ }^{23}$ A. J. Coale y S. Watkins (1986). 


\section{CUADRO 12}

\section{Evolución del indice Ig de fecundidad matrimonial}

\begin{tabular}{|c|c|c|c|}
\hline & S. XVIII & 1887 & Descenso (\%) \\
\hline $\begin{array}{llllllllll}\text { Andalucía } & \ldots & \ldots & \ldots & \ldots & \ldots & \ldots & \ldots & \ldots & \ldots\end{array}$ & 0,673 & 0,622 & 7,6 \\
\hline $\begin{array}{llllllllllll}\text { Aragón } & \ldots & \ldots & \ldots & \ldots & \ldots & \ldots & \ldots & \ldots & \ldots & \ldots\end{array}$ & 0,716 & 0,647 & 9,7 \\
\hline $\begin{array}{lllllllllll}\text { Asturias } & \ldots & \ldots & \ldots & \ldots & \ldots & \ldots & \ldots & \ldots & \ldots & \ldots\end{array}$ & 0,844 & 0,794 & 5,9 \\
\hline $\begin{array}{llllllllllll}\text { Baleares } & \ldots & \ldots & \ldots & \ldots & \ldots & \ldots & \ldots & \ldots & \ldots & \ldots\end{array}$ & 0,702 & 0,581 & 17,3 \\
\hline $\begin{array}{lllllllll}\text { Castilla la Nueva } & \ldots & \ldots & \ldots & \ldots & \ldots & \ldots & \ldots\end{array}$ & 0,653 & 0,651 & 0,3 \\
\hline $\begin{array}{lllllllll}\text { Castilla la Vieja } & \ldots & \ldots & \ldots & \ldots & \ldots & \ldots & \ldots\end{array}$ & 0,779 & 0,712 & 8,6 \\
\hline $\begin{array}{llllllllllll}\text { Cataluña } & \ldots & \ldots & \ldots & \ldots & \ldots & \ldots & \ldots & \ldots & \ldots & \ldots\end{array}$ & 0,819 & 0,534 & 34,8 \\
\hline $\begin{array}{llllllllll}\text { Extremadura } & \ldots & \ldots & \ldots & \ldots & \ldots & \ldots & \ldots & \ldots & \ldots\end{array}$ & 0,702 & 0,688 & 2,0 \\
\hline $\begin{array}{lllllllllll}\text { Galicia } & \ldots & \ldots & \ldots & \ldots & \ldots & \ldots & \ldots & \ldots & \ldots & \ldots\end{array}$ & 0,757 & 0,695 & 8,2 \\
\hline $\begin{array}{lllllllllll}\text { León } & \ldots & \ldots & \ldots & \ldots & \ldots & \ldots & \ldots & \ldots & \ldots & \ldots\end{array}$ & 0,807 & 0,689 & 14,6 \\
\hline $\begin{array}{lllllllllll}\text { Murcia } & \ldots & \ldots & \ldots & \ldots & \ldots & \ldots & \ldots & \ldots & \ldots & \ldots\end{array}$ & 0,656 & 0,622 & 5,1 \\
\hline $\begin{array}{llllllllllll}\text { Navarra } & \ldots & \ldots & \ldots & \ldots & \ldots & \ldots & \ldots & \ldots & \ldots & \ldots\end{array}$ & 0,769 & 0,669 & 13,0 \\
\hline 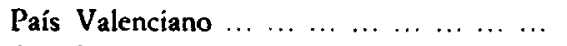 & 0,644 & 0,640 & 0,5 \\
\hline $\begin{array}{lllllllllll}\text { País Vasco } & \ldots & \ldots & \ldots & \ldots & \ldots & \ldots & \ldots & \ldots & \ldots\end{array}$ & 0,762 & 0,692 & 9,2 \\
\hline
\end{tabular}

Fuentes: Cuadro 10 y A. J. Coale y S. Watkins (1987).

\section{Agradecimiento}

El presente trabajo ha sido realizado en el marco de los proyectos de investigación PB85-0222 y PS87-0067, aprobados por la Comisión Interministerial de Ciencia y Tecnología y la Dirección General de Investigación Científica y Técnica, respectivamente. 


\section{BIBLIOGRAFIA}

ANEs, G. (ed.) (1982): La economia española al final del Antiguo Régimen. I. Agricultura, Madrid, Alianza Editorial y Banco de España.

Anes, G., ef al. (1982): España a finales del siglo XVIII, Tarragona, Hemeroteca.

Bengtsson, T.; Fridlizius, G., y Ohlsson, R. (eds.) (1981): Pre-Industrial Population Change. The Mortality Decline and Short-Term Population Movements, Estocolmo, Almquist and Wiksell International.

Bl.Ayo, Y. (1975): «La mortalité en France de 1740 à 1829», Population, número especial: Démographie Historique.

Bustelo, F. (1972a): aAlgunas reflexiones sobre la población española de principios del siglo Xvilı", Anales de Economia, XV.

- (1972 b): «La población española en la segunda mitad del siglo xvili», Moneda y Crédito, 123.

- (1974): «Introducción ao estudo cuantitativo da poboación galega no século xviri», Grial, 45.

- (1975): «La població del País Valencià al segle xvill», Recerques, 5.

- (1976): «La población de Cataluña en el siglo xvıı», Hacienda Pública Española, 38.

Cachinero, B. (1985): "Estimating Levels of Adult Mortality in Eighteenth-Century Spain», Historical Methods, 18 (2).

Castelló Traver, J. E. (1978): El Pais Valenciano en el Censo de Floridablanca, Valencia, Institución Ảlfonso el Magnánimo.

Censo español executado de orden del rey comunicada por el excelentisimo señor Conde de Floridablanca, primer secretario de Estado y de despacho, en el año de $1787, \mathrm{Ma}$. drid; edición facsímil, Madrid, INE, 1981.

Censo de la población de España de el año de 1797, executado de orden del rey en el de 1801, Madrid.

Conle, A. J., y Trussell, J. (1974): «Model fertility schedules: variations in the structure of childbearing in human populations», Populations Index, 40.

- (1975): «Erratum», Population Index, 41.

Coale, A. J., y Watkins, S. C. (eds.) (1986): The Decline of Fertility in Europe, Princeton University Press.

Dopico, F. (1987): «Regional Mortality Tables for Spain in the 1860s», Historical Methods, 20 (4).

Eiras Roel, A. (1982): "Problemas demográficos del siglo xvill», en G. Anes et al.

Estudis sobre la població del Pais Valencià. Actes de les I Jornades d'Estudi sobre la Població del País Valencià (1988), Valencia, Alfons el Magnànim, Institut Juan Gil-Albert y Seminari d'Estudis sobre la Població del País Valencià, Valencia, 2 vols.

FERnÁndez de Pinedo, E. (1974): Crecimiento económico y transformaciones sociales del Pais Vasco (1100-1850), Madrid, Siglo XXI.

- (1980): “Coyuntura y política económicas», en E. Fernández de Pinedo, A. Gil Novales y A. Derozier, Centralismo, Ilustración y agonía del Antiguo Régimen (1715. 1833), Madrid, Labor.

Garcín Sanz, A. (1977): Desarrollo y crisis del Antiguo Régimen en Castilla la Vieja. Economia y sociedad en tierras de Segovia de 1500 a 1814, Madrid, Akal.

García Sanz-Marcotegui, A. (1985): Demografia y sociedad en la Barranca de Navarra (1760-1860). Pamplona, Gobierno de Navarra.

Glass, D. V., y Revel.le, R. (1978): Población y cambio social. Estudios de demografia bistórica, Madrid, Tecnos.

Grupo 75 (1977): La economia del Antiguo Régimen. La urenta nacional de la Corona de Castilla, Madrid, Universidad Autónoma.

Hernández Marco, J. L., y Piquero Zarauz, S. (1988): «Informe sobre el estado de la cuestión demográfica vasca (1500-1850)», en V. Pérez Moreda y D.S. Reher (eds.).

Iglesies, J. (1969.70): El Cens del comle de Floridablanca, 1787 (part de Catalunya), Barcelona, 2 vols. 
Jiménez de Gregorio, F. (1980): La pohlación de la actual provincia de Madrid en el Censo de Floridablanca (1786), Madrid.

Keyfitz, N. (1977): Applied Mathematical Demograpby, Nueva York, John Wiley.

LEE, W. R. (ed.) (1979): European Demography and Economic Growth, Londres.

Leridon, H., y Menken, I. (eds.) (1979): Natural Fertility, Lieja, Ordina.

Livi BACCI, M. (1968): "Fertility and Nupciality Changes in Spain from the Late 18th to the Early 20th Century», Population Studies, XXII ( 1 y 2).

- (1978): "La fecundidad y el crecimiento demográfico en España en los siglos Xviı y xIX", en D. V. Glass y R. Revelle (eds.).

- (1987): «Il censimento di Floridablanca nel contesto dei censimenti europei», Genus, XLIII (3.4).

LloBet, S. (1947): "La población de Barcelona en 1787», Estudios Geográticos, 27.

Lluch, E. (1981): «El cens del comte de Floridablanca de 1787 (part de la Vall d'Aran)w, Recerques, 11.

Moll, I.; Segura, A., y Sunu, J. (1983): Cronologia de les crises demográfiques a Mallorca. Segles XVIII-XIX, Palma de Mallorca, Institut d'Estudis Balearics.

Moreno Almarcegui, A.; Soler Serratosa, J., y Fuentes Robles, F. (1984): «Introducción al estudio sociodemográfico de Cataluña mediante el censo de Floridablanca (1787)», en Actes del I Congrés d'Historia Moderna de Catalunya.

Naciones Unidas (1970): El concepto de población estable. Aplicación al estudio de la población de paises que no tienen buenas estadisticas demográficas, Nueva York.

NADAL, J. (1984): La población española (Siglos XVI a XX), edición corregida y aumentada, Barcelona, Ariel.

Pérez, J. M., y Ardit Lucas, M. (1988): «Bases del crecimiento de la población valenciana en la Edad Moderna", en Estudis sobre la població..., vol. I.

Pérez Moreda, V. (1980): Las crisis de morlalidad en la España interior. Siglos XVI-XIX, Madrid, Siglo XXI.

- (1986): «Matrimonio y Familia. Algunas consideraciones sobre el modelo matrimonial español en la Edad Moderna», Boletín de la Asociación de Demografía Histórica, IV (1).

- (1985): «La evolución demográfica española en el siglo xix (1797-1930): tendencias generales y contrastes regionales", en Società Italiana de Demografia Storica.

Pérez MoredA, V., y Reher, D.S. (eds.) (1988): Demografia Hislórica en España, Madrid, El Arquero.

Pérez SARrión, G. (1984): „El censo de Floridablanca en Aragón: un análisis general», Revista de Historia Económica, II (3).

Rodríguez Galdo, M. X.: "Los comienzos de la transición demográfica en Galicia» (en prensa).

Rodríguez Sánchez, A. (1988): "La población de Extremadura en el siglo xvil», en Estudis sobre la població..., vol. I.

RowLAND, R. (1984): «Sistemas familiares e padrōes demográficos em Portugal: Questões para uma investigaçāo comparada", Ler História, 3.

- (1988): «Sistemas matrimoniales en la Península Ibérica (siglos xVI-xix): Una perspectiva regional», en V. Pérez Moreda y D.S. Reher (eds.).

- (s. f.): «El Censo de Floridablanca y la historia de las poblaciones europeas», en II Centenario del Censo de Floridablanca, Madrid, INE (en prensa).

Ruiz Almansa, J. (1947): «El censo de población de España de 1797», Revista Internacional de Sociologia, 5.

Sanzo Fernández, C. M. (1982): «La población de Asturias en los siglos XVII a XIX: los registros parroquialesw, en $G$. Anes (ed.).

Sivamurthy, M. (1982): Growth and Structure of Human Population in the Presence of Migration, Academic Press.

Societá Itallana di Demografia Storica (1985): La popolazione italiana nell'Ottocento. Continuità e mutamenti, Bolonia, Clueb.

Trussell, J. (1979): "Natural fertility: measurement and use in fertility models», en H. Leridon y J. Menken (eds.). 
Vidal Bendito, T., y Gomila Huguet, J. (1986): «Aproximación a la demografía histó. rica menorquinam, Boletin de la Asociación de Demografia Histórica, IV (2).

Vilar, P. (1964-68): Catalunya dins l'Espanya moderna, Barcelona, Edicions 62.

- (1965): «Quelques problèmes de démographie historique en Catalogne et en Espagne», Annales de Démographie Historique.

WRIGLEY, E. A. (1985): "The lall of marital fertility in nineteenth-century France: exemplar or exception?», European Journal of Population, 1.

WRIGley, E. A., y SChofIELD, R. S. (1981): The Population History of England, 1541. 1871. A reconstruction, Londres, Arnold. 